\title{
Simultaneous monitoring of physiological and behavioural activity in marine organisms using non-invasive, computer-aided techniques
}

\author{
A. Aagaard, B. B. Andersen, M. H. Depledge \\ Institute of Biology, Odense University, DK-5230 Odense M, Denmark
}

\begin{abstract}
A computer-aided monitoring system is described which permits continuous long-term recording of cardiac and respiratory activity together with locomotor activity in selected aquatic organisms. Four macroinvertebrates can be studied simultaneously using the apparatus described. However, with additional hardware (respirometry chambers, valves, oxygen electrodes and infra-red sensors), the system can readily be expanded for use with 20 or more organisms using a single computer (PC). Data are acquired using non-invasive sensors thereby subjecting test organisms to minimal stress Examples of the type of data that have been obtained during the first $2000 \mathrm{~h}$ of operation are provided.
\end{abstract}

\section{INTRODUCTION}

Ecological studies invariably highlight the differential abilities or organisms to cope with fluctuations (either physico-chemical or biological) in their environment. Very often, such differences reflect differences in physiological repertoires among individuals (Feder 1987, Depledge 1990).

Early attempts to monitor physiological processes in aquatic organisms usually involved selection of a variable, for example heart rate, oxygen consumption or filtration rate, which was then measured consecutively in individual organisms held under similar controlled conditions (e.g. Vernberg et al. 1974, Vernberg et al. 1977). Often, the transduction of physiological data involved invasive procedures such as electrode implantation, which themselves gave rise to physiological disturbance (Cumberlidge \& Uglow 1977). In recent years the limitations imposed by earlier procedures have been alleviated by new techniques which allow non-invasive monitoring of certain rate processes in selected invertebrates using computer-aided data acquisition and storage systems (Steffensen et al. 1984, Depledge \& Andersen 1990). Such approaches permit long-term (weeks or months) recordings to be obtained with minimal disturbance of experimental organisms (Aalto \& Smede 1985, Depledge \& Andersen 1990). Furthermore, computer-aided recording allows data acquired from several animals simultaneously to be stored in a convenient form for later analysis.
To refine physiological monitoring still further, it is desirable to be able to monitor more than one physiological variable together with behavioural activity, $24 \mathrm{~h}$ per day for prolonged periods under a variety of experimental conditions. Data obtained may be used to identify interrelations between variables and recognition of more sensitive indices of physiological perturbation. For example, Depledge (1982) suggested that by examining changes in the relationships between the measured variables such as heart rate/oxygen consumption ratios, subtle disturbances of physiology might be more readily detected.

The current paper describes a computer-aided monitoring system permitting simultaneous measurement of heart rate, oxygen consumption and locomotor activity in 4 animals for extended periods (days or weeks).

\section{MATERIALS AND METHODS}

System overview. A schematic representation of the system is shown in Fig. 1. The procedures described below were established using the shore crab Carcinus maenas as the test species. However, a variety of other organisms can be studied using this system or a modified version of it (see Riisgaard 1991).

Four flow-through respirometry chambers are maintained in a temperature-controlled water bath. The oxygen tension in each respirometry chamber is meas- 


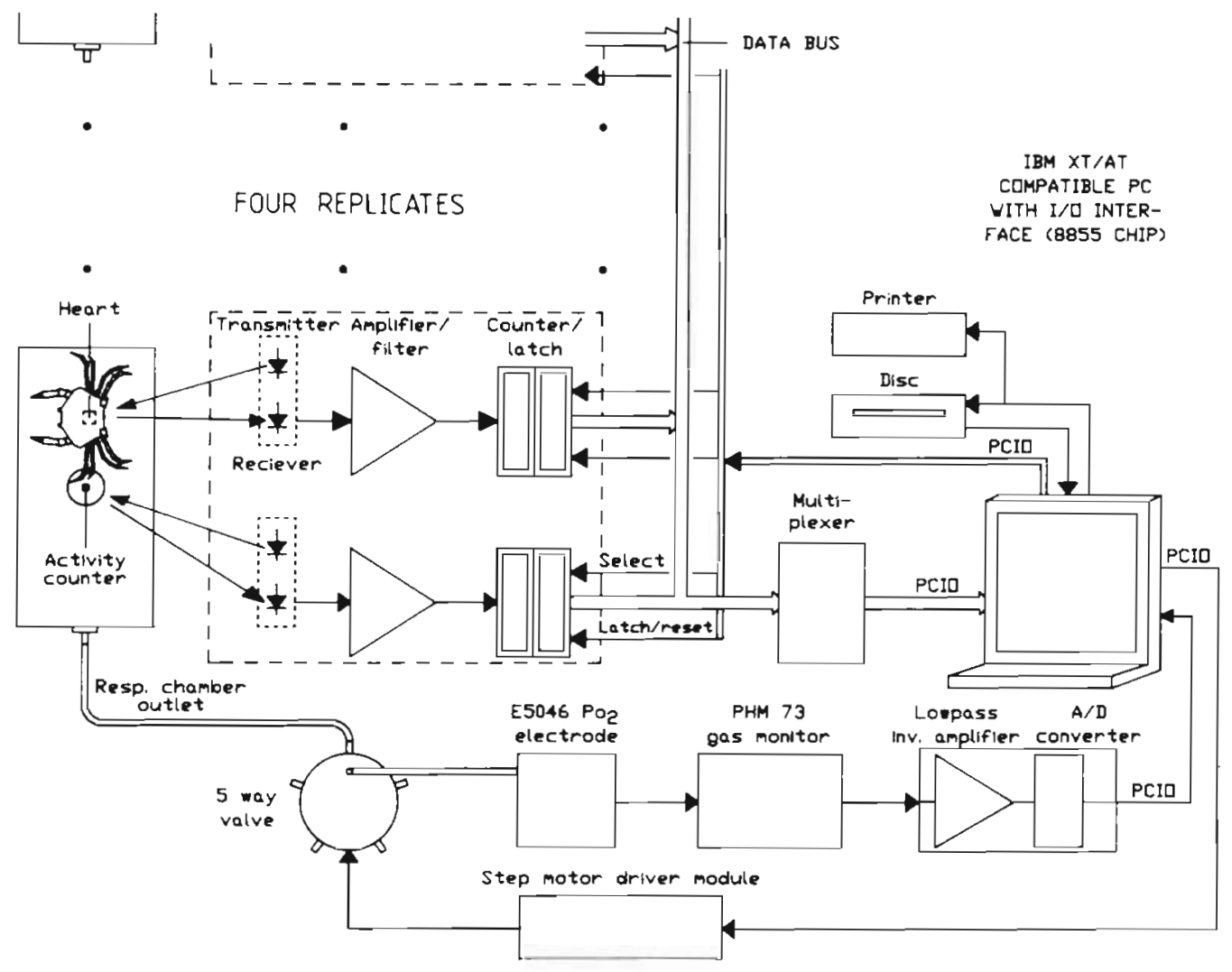

Fig. 1 Overview of the 4-channel computer-aided monitoring system. Heart rate, oxygen consumption and locomotor activity can be monitored for indefinite periods. Data are displayed in real time and are stored on computer discs for subsequent analysis ured by diverting flow through a 5-way valve into a single oxygen electrode interfaced to a standard IBM compatible computer (PC). The transparent floor of each respirometry chamber is fitted with an infra-red light emitter/detector permitting movements of organisms within the chamber to be detected. These sensors are also interfaced with the computer. Cardiac activity of test crabs is recorded non-invasively using infra-red emitter/detectors as previously described by Depledge \& Andersen (1990). All data acquired is graphically displayed in real time and stored on disc for later analysis.

Flow respirometers. Oxygenated water from a collecting aquarium is pumped up into a 101 aquarium (Fig. 2). This reservoir is fitted with outlets allowing gravity feed through silicon tubing $(3.0 \mathrm{~mm}$ diameter) into each of the 4 respirometry chambers (each ca 21 capacity). Each chamber is fitted with an overflow pipe and an outlet port (Fig 2). Plastic covers ( $5 \mathrm{~mm}$ thick) are floated on the surface of the water in each respirometry chamber to exclude oxygen uptake from the surrounding air. The outlet ports from each chamber are connected to a 5-way valve. This permits flow (at ca $5 \mathrm{ml} \mathrm{min}^{-1}$ ) from the 4 chambers and from the reservoir to be successively directed past a single oxygen electrode (Type E5046, Radiometer, Copenha- gen) mounted in a thermostatically-controlled cell (Type D616, Radiometer, Copenhagen). Water passing from the electrode chamber is collected together with water from respirometer overflow pipes, and returned to the collecting aquarium (Fig. 2). The reservoirs, respirometers, connecting tubes and the oxygen cell are all immersed in a thermostatically-controlled water bath to ensure temperature uniformity. The total volume of the system is ca $28 \mathrm{I}$.

Flow through the respirometry chambers is sufficiently rapid and turbulent to ensure that water is well mixed and uniformly oxygenated. Furthermore, flow can be roughly matched to the oxygen demands of each experimental individual by adjusting the height of each chamber relative to the reservoir aquarium (Fig. 2). This ensures that a suitable drop in oxygen tension (i.e. easily measurable, but not so severe as to elicit physiological responses) can be established. Tests of the system were carried out using male shore crabs Carcinus maenas ( $30 \mathrm{~g}$ wet weight) using a flow rate of $2 \mathrm{I} \mathrm{h}^{-1}$. At this rate, a $95 \%$ washout of the respirometers took place within $4 \mathrm{~h}$ (cf. Steffensen 1989). When running in closed circuit, oxygen tension in the respirometer chambers was allowed to fall from saturation $(150 \mathrm{~mm} \mathrm{Hg})$ to between 120 and $130 \mathrm{~mm} \mathrm{Hg}$.

Control of the 5-way valve. Connections into and out 
Fig. 2. The flow respirometer, ra: reservoir aquarium; o: overflow from respirometer; rc: respirometer chambers; $\mathrm{v}$ : 5-way valve; e: $\mathrm{Po}_{2}$ electrode; ca: collecting aquarium; p: pump

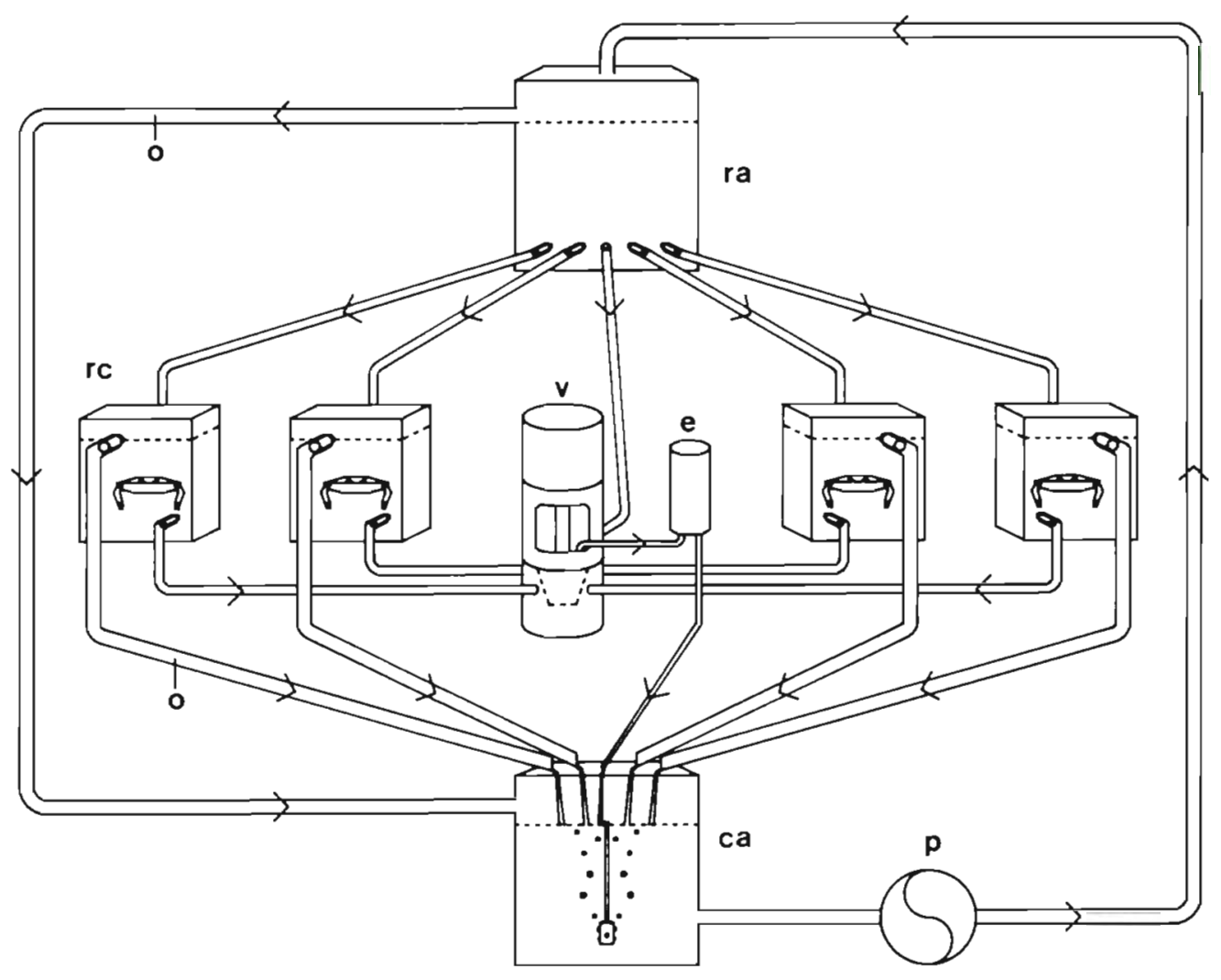

of the specially constructed 5-way valve are shown in Figs. $1 \& 3$. Inlets are located in a plexiglass collar. A single outlet is situated in a rotating cone which revolves on a thin layer of silicon grease lining the collar. The cone is held in place by a bolt to ensure that the valve is water-tight. The rotation of the cone is controlled using a step motor (HY200-2215, MAE, Cremona, Italy) so that each of the valve inlets can be closed or aligned with the outlet port as required. This procedure is computer controlled.

Oxygen measurements and computer interfacing. To measure oxygen tension, flow is stopped $40 \mathrm{~s}$ prior to recording the value to ensure electrode stabilisation. The tension value obtained from the recorder output of the oxygen monitor (PHM73, Radiometer, Copenhagen) is input to the computer using an interface comprising a low pass inverting amplifier and an analogueto-digital (A/D) converter. An operational amplifier U1A (part of CA 082) is coupled as a standard, noninverting amplifier with no gain to regulate input impedance. U1B is coupled as a 2 -pole filter with $F 3 \mathrm{db}$ at $0.7 \mathrm{~Hz}$ in each low pass filter. U2A (part of $\mathrm{Tl}$ 082) is coupled as an inverting DC offset in front of an inverting amplifier (U2B) with an adjustable gain (P2) of 0 to 5 times. R10 - D1 - D2 is a protection circuit for the A/D converter. $\mathrm{U} 2$ is an 8 -bit A/D converter (AD 7569) with a 0 to 255 times resolution, set up in a unipolar configuration $(0$ to $+1.25 \mathrm{~V})$. The output from U2 is con- nected to Port $\mathrm{A}$ on the PCIO interface board, located in the computer. When the system is operating, data is acquired and stored with the aid of a software programme (designated CARMON - Computer-Aided Respiration Monitoring) written in Turbo Pascal (5.0)".

Monitoring cardiac activity. Cardiac activity is monitored using the CAPMON system developed by Depledge \& Andersen (1990). In brief, this system uses light-weight, small, infra-red emitter/detectors applied to the external surface of the dorsal carapace of test crabs. During the heart's cycle of action, the amount of infra-red light reflected back to the detector varies, thereby allowing heart rate (and to some extent, changes in heart beat amplitude) to be monitored. The detectors are interfaced with a PC. Using specially written software, heart activity can be monitored minute by minute, $24 \mathrm{~h}$ per day, in 4 individuals simultaneously, over prolonged periods (weeks or months) (Depledge \& Andersen 1990). In the system described here, extremely flexible, teflon-coated wires connect the infra-red transducers to the interface. Thus, sensor attachment does not interfere with either the wellbeing or the free movement of the test organisms.

Activity recordings. Several authors have investigated locomotor activity in aquatic invertebrates by

- Full details of CARMON software and electronic circuitry can be obtained from A. Aagaard 


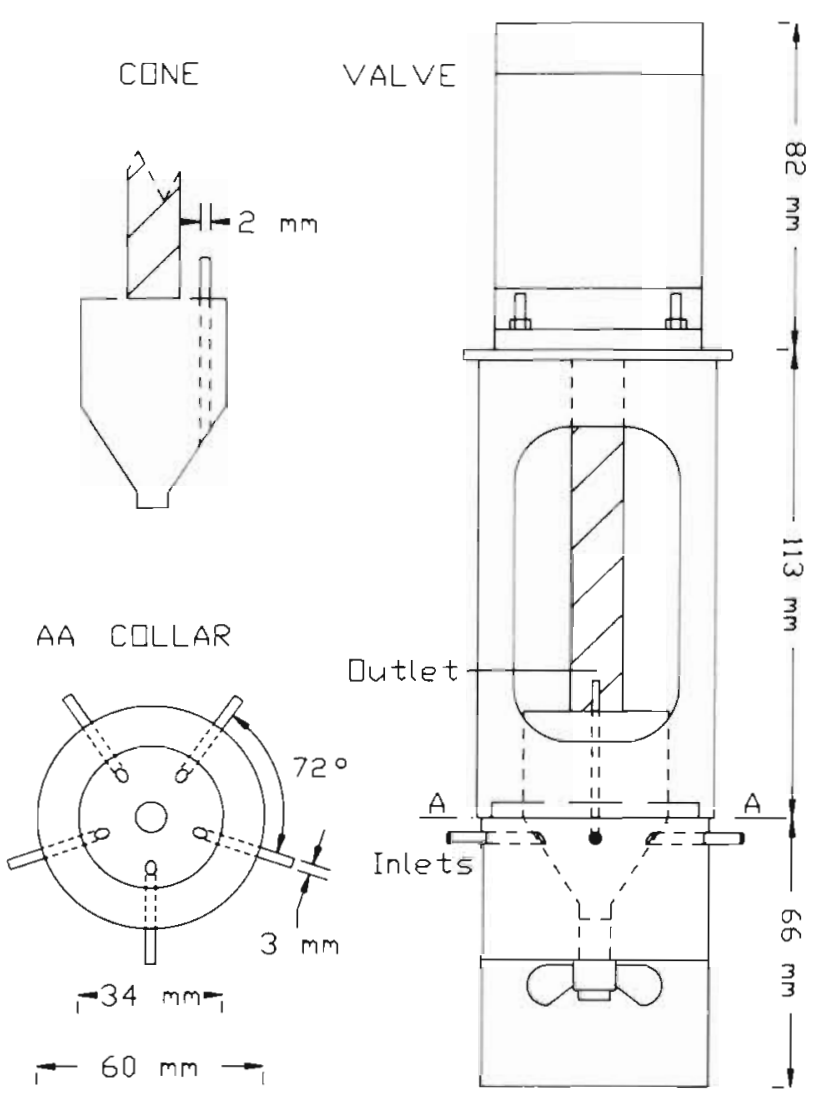

Fig. 3. The computer-controlled 5-way valve and step motor assembly

monitoring interruptions of infra-red beams passing across test aquaria (Atkinson et al. 1974, Bolt \& Naylor 1985, Williams \& Palmer 1988). A similar principle was employed here. An infra-red optocoupler was affixed centrally under the transparent floor of each respirometry chamber. The dimensions of the chamber were such that test specimens could not move significantly without interrupting the beam and reflecting infra-red light back to the detector. These events were recorded and counted using the computer system described by Depledge \& Andersen (1990). In preliminary tests using Carcinus maenas the system functioned well. The crabs tended to move around the respirometry chamber when active, repeatedly breaking the light beam. When not carrying out locomotor activity, only occasional movements of chelae or legs were observed and these seldom interrupted the light beam.

\section{RESULTS}

\section{Evaluation of the system}

Comparison of Winkler titration determinations of oxygen with values measured using the oxygen elec- trode confirmed the precision and accuracy of the electrode. Oxygen tension in the respirometry chambers (without test animals) was identical to that of water in the reservoir. This situation persisted even when the oxygen tension in the reservoir was lowered by bubbling nitrogen through the water. This experiment also confirmed that silicone connecting tubes and the floating plastic covers in each respirometer were effective in excluding significant oxygen inflow from the surrounding air. Knowing flow rate through each respirometer, changes in oxygen tension over time, salinity and temperature, it is a simple procedure to programme the computer to calculate oxygen concentrations from the equation:

$\ln C=A_{2}+A_{2}(100 / T)+A_{3} \ln (T / 100)+A_{4}(T / 100)$ $+S\left[B_{1}+B_{2}(T / 100)+B_{3}(T / 100)^{2}\right]$

where $C=$ oxygen concentration $\left(\mathrm{cm}^{3} \mathrm{dm}^{-3}\right) ; S=$ salinity $(\%) ; \quad T=$ absolute temperature $(\mathrm{K}) ; A_{1}=$ $-173.4292, A_{2}=249.6339, A_{3}=143.3483 ; B_{1}=$ $-0.033096, B_{2}=0.014259, B_{3}=-0.00170$. (Based on data provided by Riley \& Skirrow 1975). Oxygen consumption values for the test organisms are calculated every 20 min by the computer.

The system has now run in excess of $2000 \mathrm{~h}$ without difficulty. Data from preliminary experiments in which endogenous rhythms in behaviour and physiology of shore crabs were investigated together with pollutant effects will be reported elsewhere (Aagaard et al. unpubl.). However, representative examples of the type of information that can be obtained are shown in Fig. 4 and Table 1. Fig. 4 a illustrates simultaneous changes in respiration rate, heart rate and locomotor activity in a shore crab Carcinus maenas held in constant conditions for $72 \mathrm{~h}$ after collection from the seashore. Subsequent periodogram analysis (Enright 1965) of locomotor activity revealed tidal and diurnal rhythms with peaks coinciding with high tide and darkness (Fig. 4b). Interestingly, there is evidence that whilst short-term fluctuations in heart rate and locomotor activity were closely correlated with each other, changes in respiration rate followed more slowly (to be reported more fully by Aagaard et al. unpubl.). Table 1 summarises data recorded from 4 crabs prior to and following exposure to $1 \mathrm{ppm}$ copper ions. Heart rate increased markedly whilst oxygen consumption and activity level did not alter significantly $(p<0.05)$.

\section{DISCUSSION}

Attempts to monitor the physiology of invertebrate organisms began almost 25 yr ago. Much of the impetus behind such research came from the desire to detect sublethal effects of natural stress factors and 

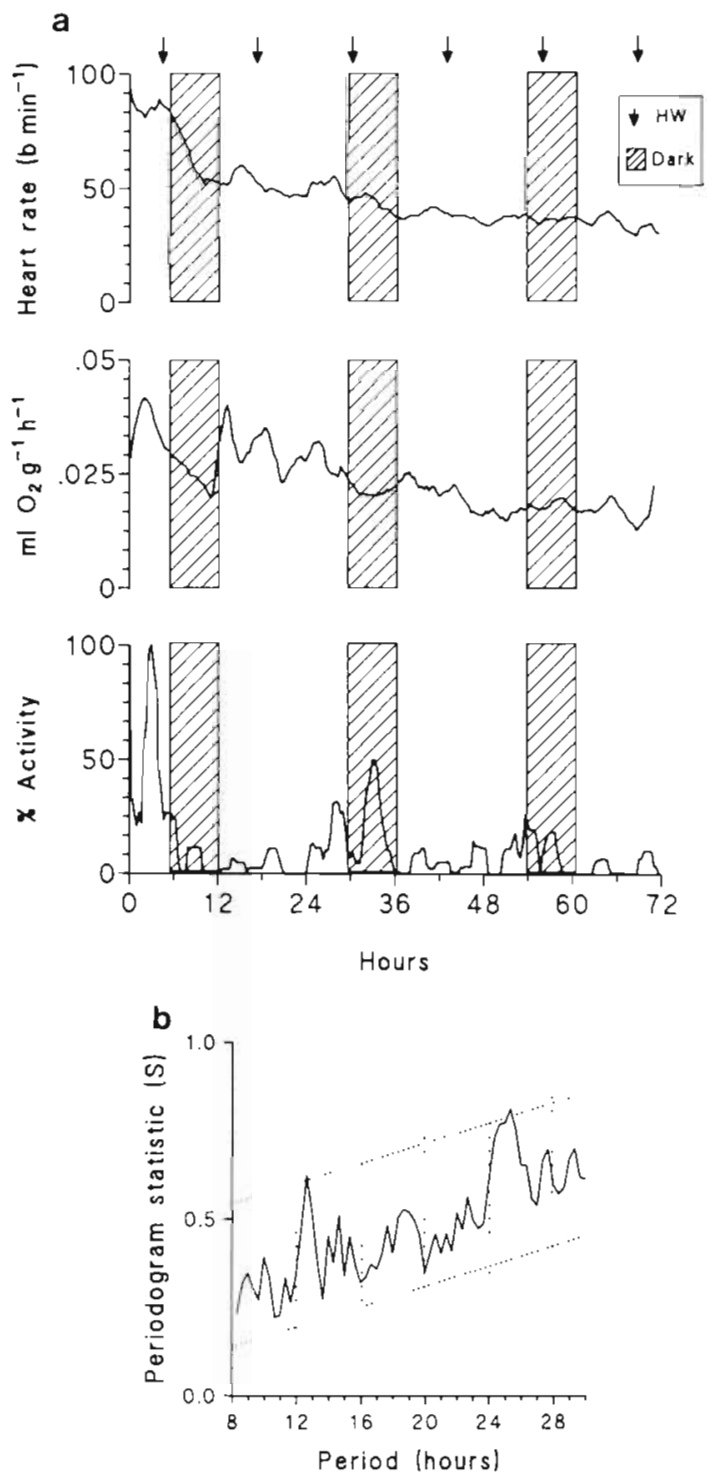

Fig. 4. Carcinus maenas. Changes in heart rate, oxygen consumption and locomotor activity of an individual male $(31 \mathrm{~g}$ fresh weight) during the $72 \mathrm{~h}$ following collection and transfer to the monitoring system $\left(16^{\circ} \mathrm{C}\right.$, flow rate $\left.2 \mathrm{l} \mathrm{h}^{-1}\right)$. (a) Simultanoues changes in cardiac, respiratory and locomotor activity. (b) Periodogram analysis of locomotor activity data showing significant tidal and diurnal rhythms. Dotted lines represent $\pm 95 \%$ confidence limits of the regression line derived from the randomisation of the same date (Williams \& Naylor 1978)

pollutants. For example, Thurberg et al. (1974) monitored oxygen consumption in bivalves, Andersen et al. (1977) monitored heart rate and hatching success in estuarine fish exposed to petroleum hydrocarbons, and Depledge (1984 a, b) monitored cardiac and respiratory activity in crabs exposed to sublethal concentrations of hydrocarbons, dispersants, copper and mercury under a variety of environmental conditions. These early studies were severely hampered by the lack of suitable
Table 1. Carcinus maenas. Influence of copper exposure $(1 \mathrm{ppm})$ on locomotor activity, heart rate and oxygen consumption in the shore crab $(n=4)$

\begin{tabular}{|lcc|}
\hline Parameter & $\begin{array}{c}\text { Prior to } \\
\text { exposure }\end{array}$ & $\begin{array}{c}\text { Following } \\
\text { exposure }\end{array}$ \\
\hline $\begin{array}{l}\text { Locomotor activity } \\
\text { (counts per 20 min) }\end{array}$ & $1.94 \pm 1.33$ & $3.26 \pm 1.51$ \\
$\begin{array}{l}\text { Heart rate } \\
\text { (beats per min) } \\
\mathrm{O}_{2} \text { consumption } \\
\left(\mu l \mathrm{~g}^{-1} \mathrm{~h}^{-1}\right)\end{array}$ & $30.5 \pm 11.1$ & $\cdot 83.5 \pm 10.8$ \\
$\cdot \mathrm{p}<0.05$ & $84.0 \pm 14.0$ & $70.0 \pm 7.0$ \\
\hline
\end{tabular}

transducers capable of recording data over long periods (weeks or months), from several test organisms simultaneously without imposing undue stress. Recent technological developments have done much to alleviate these difficulties.

The computer-aided system described here is relatively simple and inexpensive to construct. Furthermore, running costs are minimal and the system can easily be operated by technical staff after brief introductory training. The CARMON software is sufficiently flexible to be adapted for a range of monitoring uses and additional data may be readily input and handled (for example, monitoring an additional variable such as scaphognathite beat frequency or inputing data from serial blood sample analyses). The use of the computer to divert flow from each respirometer past a single oxygen electrode at appropriate intervals, and the selfcalibration of the electrode are major advantages of the design. Currently, the system is being used in our laboratory to investigate the relationships between physiological state and pollutant effects (in particular, the toxicity of selected trace metals). Because longterm monitoring studies can be carried out, it is now feasible to examine the progressive, insidious impact of pollutants over time on physiological parameters (cardiac and respiratory activity), locomotor activity and ecologically-relevant parameters such as growth rate. A portable version of the system is now being developed to facilitate deployment at a range of locations including water treatment centres and coastal field study sites.

Both industry and environmental protection agencies have long been aware of the potential role of physiological/behavioural monitoring (see e.g. Aalto \& Smede 1985), but it is only recently that the importance of incorporating such techniques in ecotoxicology programmes has been highlighted (Depledge 1990). Marine organisms exposed to pollutants may exhibit behavioural responses (altered activity, avoidance, etc.) 
and or compensatory physiological responses (altered metabolism, etc.). In severe cases, pollutant toxicity gives rise to pathophysiological responses resulting in morbidity and mortality. The time course of all these responses may range from hours to months following pollutant exposure. The computer-aided monitoring system described here is an attempt to provide a practical means by which such pollutant-induced effects can begin to be studied more effectively.

Acknowledgements. We gratefully acknowledge financial support for this research programme from the Danish Science Council, the Carlsberg Foundation and Dansk Shell A/S.

\section{LITERATURE CITED}

Aalto, E., Smede, S. (1985). Bioelectric analyser for raw water monitoring. In: Proc. XIV Int. Conf. Medical and Biological Engineering, Med \& Biol. \& Comp. 23: 111-112

Andersen, J. W., Dixit, D. B., Ward, G. S., Foster, R. S. (1977). Effects of petroleum hydrocarbons on the rate of heart beat and hatching success of estuarine fish embryos. In: Vernberg, F. J., Calabrese, A., Thurberg, F. P., Vernberg, W. B (eds.) Physiological responses of marine biota to pollutants. Academic Press, New York, p. 241-258

Atkinson, R. J. A., Bailey, H., Naylor, E. (1974). Some laboratory methods for recording and displaying temporal patterns of locomotor activity in marine animals. Mar. Behav. Physiol 3: 59-70

Bolt, S. R. L., Naylor, E. (1985). Interaction of endogenous and exogenous factors controlling locomotor activity rhythms in Carcinus maenas exposed to tidal salinity cycles. J. exp. mar. Biol. Ecol. 85: 47-56

Cumberlidge, N., Uglow, R. G. (1977). Heart rate and scaphognathite activity in the shore crab Carcinus maenas (L.). J. exp mar. Biol. Ecol. 28: 87-107

Depledge, M. H. (1982). Sublethal and synergistic effects of environmental factors and pollutants on the circulatory and respiratory physiology of the shore crab, Carcinus maenas (L.). Ph.D. thesis, University of London

Depledge, M. H. (1984a). Disruption of circulatory and respiratory activity in shore crabs (Carcinus maenas) exposed to heavy metal pollution. Comp. Biochem. Physiol. $78 \mathrm{C}: 445-459$

Depledge, M. H. (1984b). Changes in cardiac activity, oxygen

This article was submitted to the editor uptake and perfusion indices in Carcinus maenas (L.) exposed to crude oil and dispersant. Comp. Biochem. Physiol. 78C: $461-466$

Depledge, M. H. (1990). New approaches in ecotoxicology: can interindividual physiological variability be used as a tool to investigate pollution effects? Ambio 19: 251-252

Depledge, M. H., Andersen, B. B. (1990). A computer-aided physiological monitoring system for continuous, long-term recording of cardiac activity in selected invertebrates Comp. Biochem. Physiol. 96A: 473-477

Enright, J. T (1965). Accurate geophysical rhythms and frequency analysis. In: Aschoff, J. (ed.) Circadian clocks. North Holland, Amsterdam, p. 31-42

Feder, M. E. (1987). The analysis of physiological diversity: the prospects for pattern documentation and general questions in ecological physiology. In: Feder, M. E., Bennett, A. F., Burggren, W. W., Huey, R. B. (eds.) New directions in ecological physiology. Cambridge University Press, Cambridge, p. 38-75

Riisgaard, H. U. (1991). Suspension feeding in the polychaete Nereis diversicolor. Mar. Ecol. Prog. Ser. 70: 29-37

Riley, J. P., Skirrow, G. (1975). Chemical oceanography, Vol. 3, 2nd edn. Academic Press, New York, p. 519-520

Steffensen, J. F. (1989). Some errors in respirometry of aquatic breathers: how to avoid and correct for them. Fish Physiol. Biochem. 6: 49-59

Steffensen, J. F., Johansen, K., Bushnell, P. G. (1984). An automated swimming respirometer. Comp. Biochem. Physiol. 79A: $437-440$

Thurberg, F. P., Calabrese, A., Dawson, M. A. (1974). Effects of silver on oxygen consumption in bivalves at various salinities. In: Vernberg, F. J., Vernberg, W. B. (eds.) Pollution and physiology of marine organisms. Academic Press, New York, p. 67-78

Vernberg, W. B., Decoursey, P. J., O'Hara, J. (1974). Multiple environmental factor effects on physiology and behaviour of the fiddler crab, Uca pugilator. In: Vernberg, F. J., Vernberg. W B. (eds.) Pollution and physiology of marine organisms. Academic Press, New York, p. 381-426

Vernberg, F. J., Calabrese, A., Thurberg, F. P., Vernberg, W. B. (1977). Physiological responses of marine biota to pollutants. Academic Press, New York

Williams, J. A., Naylor, E. (1978). A procedure for the assessment of significance of rhythmicity in time-series data. Int. J. Chronobiol. 5: 435-444

Williams, B. G., Palmer, J. D. (1988). Comparative studies of tidal rhythms. IV Spontaneous frequency changes and persistence in the locomotor rhythms of an intertidal crab. Mar. Behav. Physiol 13: 315-332

Manuscript first received: January 24, 1991

Revised version accepted: April 29, 1991 